\title{
Mycelial Growth of Paecilomyces hepiali in Various Agar Media and Yield of Fruit Bodies in Rice Based Media
}

\author{
Alfred Chioza, Shoji Ohga \\ Department of Agro-Environmental Sciences, Faculty of Agriculture, Kyushu University, Fukuoka, Japan \\ Email: ohga@forest.kyushu-u.ac.jp
}

Received September 3, 2013; revised October 1, 2013; accepted October 7, 2013

Copyright (c) 2013 Alfred Chioza, Shoji Ohga. This is an open access article distributed under the Creative Commons Attribution License, which permits unrestricted use, distribution, and reproduction in any medium, provided the original work is properly cited.

\begin{abstract}
Growth of Paecilomyces hepiali in various agar media and yield of fruit bodies in rice based media were studied. The best growth in agar media was obtained at $25^{\circ} \mathrm{C}(61.86 \mathrm{~mm}$ colony diameter in 14 days). The initial agar media $\mathrm{pH}$ range from 6 to 8 was found to be the most favourable for mycelial growth. This study found that agars made with powders of cereal grains alone do not support good mycelial growth of $P$. hepiali. Addition of peptone improved mycelial growth significantly. The most favourable carbon sources were Mannose, Fructose and Glucose. Organic nitrogen sources were found to be the most preferred. The results demonstrated that brown rice is better than polished rice in yield of fruit bodies. Addition of peptone was found to be quite significant in enhancing yield of fruit bodies. Peptone, as a supplement, gave a better yield than addition of egg yolk, albumen and a mixture of the two. The medium with $40 \mathrm{~g}$ brown rice, $0.325 \mathrm{~g}$ glucose, $0.65 \mathrm{~g}$ sucrose, $2 \mathrm{~g}$ peptone and $65 \mathrm{ml}$ corn steep liquor was found to be the most favourable and it yielded $19.3 \mathrm{~g}$ of fresh fruit bodies.
\end{abstract}

Keywords: Agar Media; Cereal Grains Agar; Mycelial Growth; Paecilomyces hepiali

\section{Introduction}

Paecilomyces hepiali is one of the most popular fungi isolated from natural Ophiocordyceps sinensis. Until recently, this fungus had been regarded as one of the true anamorphs of $O$. sinensis. Mycologists have reported the isolation of more than 10 fungal species from natural $O$. sinensis. The isolations have resulted in the commercialization of several mycelia fermentation products that are used to supplement the limited availability of wild $O$. sinensis [1]. For instance, JinShuiBao capsule, the commercial product of Cs-4 (Paecilomyces hepiali, a standardized mycelium of $O$. sinensis) has been used in clinics throughout China. Synnematum sinensis, Cephalosporum sinensis, Gliocladium roseum, and Mortierella hepialid, the fungus strains isolated from natural $O$. sinensis, have also been subjected to large-scale fermentation and are used as commercial products [2]. Most of the recent studies are reporting Hirsutella sinensis as a generally accepted anamorph of $O$. sinensis [3-6].

Ophiocordyceps sinensis, (Berk.) (G.H. Sung, J.M. Sung, Hywel-Jones \& Spatafora) is one of the most popular and highly valued medicinal fungi. In 2007 it was transferred to a new family Ophiocordycipitaceae and genus Ophiocordyceps from the previous family Clavicipitaceae and genus Cordyceps as described in the phylogenetic study conducted by Sung et al. [3]. Its fruit body extends from the mummified carcass of an insect larvae, the Himalayan moth, Thitarodes armoricanus (Hepialis armoricanus). In nature, it is found only at alpine pastures in north-west and central Himalayan region [7]. This fungus is called "Dong Chong Xia Cao" (Winter-Worm-Summer-Grass) in Chinese and "Tochukaso" in Japanese. In Nepal, Bhutan, and India, it is popularly known as "Yartsagumba", "Yartsa Goenbub", and "Keera Jhar", respectively [2].

The mycelial powder of $P$. hepiali has been intensively studied and developed into functional food in China for many years. Polysaccharides, adenosine and cordycepin in the mycelial powder of $P$. hepiali are considered as the major functional compositions for the health effects [8]. Studies have shown that $P$. hepiali can inhibit tumor proliferation, invasion, metastasis, and neovascularisation, induce apoptosis, reverse drug resistance, enhance immunity, and protect hepatic function [9].

Pure cultures of various fungi have been isolated and are being maintained in various laboratories around the 
World. These cultures are mostly maintained in a variety of agar media in petri dishes/plates or test tube slants. Continuous explorations on mycelial growth of various fungi in agar media are, therefore, still necessary. This ensures availability of many options of agar media recipes which are favourable for mycelial growth of a particular fungus. As Stamets [10] pointed out, a strain grown on one medium always adapts to it, and may lose its innate ability to digest larger, more complex and variable substrates.

Most of the dietary supplements and medicinal products from mushrooms are made only from artificially grown mycelium. Apart from the extra effort required to produce the fruit body, some mushrooms do not contain any better amounts of bioactive compounds in their fruit body than the mycelium. Therefore, it is not necessary to produce fruit bodies for such mushrooms. Holliday et al. [11] reported that formation of the fruit body in artificial cultivation of $O$. sinensis does not result in any significant change to the analytical chemistry profile found in its mycelium. However, New Chapter Inc. [12] indicates that the full health benefits of a medicinal mushroom can be obtained through a combination of all the stages of its life-cycle which include mycelium, fruit bodies, spores and their extracellular compounds. It is for this reason that we think it is still necessary to continue with the pursuit for better fruiting methods of $P$. hepiali.

\section{Materials and Methods}

\subsection{Fungal Material}

The fungal strain used in this study was obtained from the mushroom culture bank at the Laboratory of Forest Production Control, Kyushu University. It is assigned to accession number KUMB108 in the culture bank. The strain was originally brought from Jilin Agricultural University, China. After genetic analysis its internal transcribed spacer (ITS) sequence was found to be an exact match (100\%) of NCBI Gene bank entry EF555097.3Paecilomyces hepiali strain Ph-4Qinghai. In the NCBI Gene bank this strain had been recorded as Ophiocordyceps sinensis Ph-4Qinghai before being updated to Paecilomyces hepiali strain Ph-4Qinghai.

\subsection{Growth in Agar Media}

Effect of temperature and initial $p H$ on mycelial growth

To determine the most favourable temperature for mycelial growth of $P$. hepiali, $5 \mathrm{~mm}$ diameter agar plugs with actively growing mycelium were inoculated on PDA plates by placing on the centre of the PDA surface. Five inoculated plates were then incubated at each of the following temperatures: $5^{\circ} \mathrm{C}, 10^{\circ} \mathrm{C}, 15^{\circ} \mathrm{C}, 20^{\circ} \mathrm{C}, 25^{\circ} \mathrm{C}$ and $30^{\circ} \mathrm{C}$. On the $14^{\text {th }}$ day after inoculation, colony diameter measurements were made. Just as in Imtiaj et al. [13], the diameter measurement recorded for each petri dish was an average of three diameter measurements on that particular dish.

To investigate the effect of initial $\mathrm{pH}$ on mycelial growth, $\mathrm{PDA}$ media with $\mathrm{pH} 5, \mathrm{pH} 6, \mathrm{pH} 7, \mathrm{pH} 8$ and $\mathrm{pH}$ 9 were prepared. Adjustments to various $\mathrm{pH}$ levels were made using $1 \mathrm{~N} \mathrm{HCl}$ and $1 \mathrm{~N} \mathrm{NaOH}$ before autoclaving the media for 15 minutes at $121^{\circ} \mathrm{C}$. Plates were inoculated as described earlier. Measurements of colony diameter were preformed on the $14^{\text {th }}$ day of incubation at $25^{\circ} \mathrm{C}$

\section{Mycelial growth in various cereal grain agar media}

Investigation on the effect of cereal grain agar media on mycelial growth of $P$. hepiali was conducted by growing in $90 \mathrm{~mm}$ petri dishes containing the following twelve agar media:

- Brown rice agar (BRA): 20.0 g brown rice powder, $15.0 \mathrm{~g}$ agar and $1000 \mathrm{ml}$ distilled water;

- Brown rice peptone agar (BRPA): $20.0 \mathrm{~g}$ brown rice powder, $4.0 \mathrm{~g}$ peptone, $15.0 \mathrm{~g}$ agar and $1000 \mathrm{ml}$ distilled water;

- Lye agar (LA): 20.0 g lye powder, 15.0 g agar and $1000 \mathrm{ml}$ distilled water;

- Lye peptone agar (LPA): 20.0 g lye powder, $4.0 \mathrm{~g}$ peptone, $15.0 \mathrm{~g}$ agar and $1000 \mathrm{ml}$ distilled water;

- Millet agar (MA): 20.0 g millet powder, 15.0 g agar and $1000 \mathrm{ml}$ distilled water;

- Millet peptone agar (MPA): 20.0 g millet powder, 4.0 g peptone, $15.0 \mathrm{~g}$ agar and $1000 \mathrm{ml}$ distilled water;

- Oats agar (OA): $20.0 \mathrm{~g}$ oats powder, $15.0 \mathrm{~g}$ agar and $1000 \mathrm{ml}$ distilled water;

- Oats peptone agar (OPA): $20.0 \mathrm{~g}$ oats powder, $4.0 \mathrm{~g}$ peptone, $15.0 \mathrm{~g}$ agar and $1000 \mathrm{ml}$ distilled water;

- Wheat agar (WA): $20.0 \mathrm{~g}$ wheat powder, $15.0 \mathrm{~g}$ agar and $1000 \mathrm{ml}$ distilled water;

- Wheat peptone agar (WPA): $20.0 \mathrm{~g}$ wheat powder, $4.0 \mathrm{~g}$ peptone, $15.0 \mathrm{~g}$ agar and $1000 \mathrm{ml}$ distilled water;

- White sorghum agar (WSA): 20.0 g white sorghum powder, $15.0 \mathrm{~g}$ agar and $1000 \mathrm{ml}$ distilled water;

- White sorghum peptone agar (WSPA): $20.0 \mathrm{~g}$ white sorghum powder, $4.0 \mathrm{~g}$ peptone, $15.0 \mathrm{~g}$ agar and 1000 $\mathrm{ml}$ distilled water.

The media were sterilized for 20 minutes at $121^{\circ} \mathrm{C}$ before pouring into petri dishes. Three petri dishes for each of the above agar media were inoculated, at the centre, with $5 \mathrm{~mm}$ diameter agar plugs containing actively growing mycelium. The petri dishes were then incubated at $25^{\circ} \mathrm{C}$ in the dark. On the $15^{\text {th }}$ day after inoculation, measurements of colony diameters were made as previously explained.

Effect of carbon and nitrogen sources on mycelial growth

Eleven carbon sources namely cellulose, fructose, ga- 
lactose, glucose, lactose, maltose, mannitol, mannose, sorbitol, sucrose and xylose were tested. Modified mushroom complete medium (MMCM) was used for this experiment. The mushroom complete medium (20.0 g glucose, 2.0 g peptone, 2.0 g yeast extract, $1 \mathrm{~g} \mathrm{~K}_{2} \mathrm{HPO}_{4}$, 0.5 g $\mathrm{MgSO}_{4}$, 0.5 g $\mathrm{KH}_{2} \mathrm{PO}_{4}$, $20.0 \mathrm{~g}$ agar and $1000 \mathrm{ml}$ distilled water) in Shim et al. [14] was modified by removing 2 grams of yeast extract and raising the quantity of peptone from 2 to 4 grams to make MMCM. A medium for each carbon source was prepared by adding $20 \mathrm{~g}$ to the MMCM to replace glucose. A medium without carbon source served as a control. Diameter measurements of the colonies were done on the $14^{\text {th }}$ day of incubation at $25^{\circ} \mathrm{C}$ just the same way as mentioned above.

The effect of nitrogen sources (alanine, ammonium acetate, ammonium chloride, ammonium nitrate, ammonium phosphate-dibasic, ammonium phosphate-monobasic, ammonium sulphate, beef extract, calcium nitrate, glycine, arginine, L-histidine, L-methionine, peptone, potassium nitrate, urea and yeast extract) was assessed by replacing peptone in MMCM with $4 \mathrm{~g}$ of each of the nitrogen sources. A medium without nitrogen source served as control.

\subsection{Growth in Rice-Based Media}

Ten different rice-based media, as presented in Table 1, were prepared to investigate their effect on yield of fruit bodies. The method in Yang and Ohga [15] was used to prepare the substrates and cultivate the fungus to fruiting. The contents of each of the media, shown in Table 1, were put into a $300 \mathrm{ml}$ Polypropylene Conical Flask, mixed well, and then left overnight in a refrigerator at $4^{\circ} \mathrm{C}$. This was done to allow the rice to absorb water and various nutrients in the mixture. The media were then autoclaved for 30 minutes at $121^{\circ} \mathrm{C}$.

After cooling, each medium was inoculated with three $4 \mathrm{~mm}$ diameter agar plugs with actively growing $P$. hepiali mycelium. The three plugs were placed around the centre of the medium surface. Each medium was replicated three times.

The media were then incubated at $23^{\circ} \mathrm{C}$ in the dark. After full colonisation, the temperature was changed down to $17^{\circ} \mathrm{C}$ for a week to induce fruiting. Following a week of incubation at $17^{\circ} \mathrm{C}$, the temperature and humidity in the growth chamber were set to $21^{\circ} \mathrm{C}$ and $85 \%$ 95\% respectively. During this time, the media were exposed to 8 hours of fluorescent light every day. As the temperature was being reset to $21^{\circ} \mathrm{C}$, the silicone plugs which had been used to cover the openings of the Conical Flasks were removed.

\subsection{Data Analysis}

Data collected were subjected to Analysis of Variance (ANOVA) and Tukey's Multiple Comparison Test, at 5\% level of significance, using Minitab 16 statistical software.

\section{Results and Discussion}

\subsection{Effect of Temperature and Initial $\mathrm{pH}$ on Mycelial Growth}

Temperature had a significant effect on mycelial growth of $P$. hepiali (Table 2). The highest growth was obtained at $25^{\circ} \mathrm{C}$. This is same as findings reported on other fungal species namely Cordyceps nutans Pat. [16], Ophiocordyceps longissima [17], Ophiocordyceps heteropoda [18], Cordyceps cardinalis [19] and Cordyceps sinensis (now known as Ophiocordyceps sinensis) [20]. It was interest-

Table 1. Rice-based media.

\begin{tabular}{|c|c|c|c|c|c|c|c|}
\hline Media & Polished rice (g) & Brown rice (g) & Egg (g) & Glucose (g) & Sucrose (g) & Peptone (g) & Corn steep liquor (ml) \\
\hline A1 & 40 & & $20^{* 1}$ & 0.325 & 0.65 & & 65 \\
\hline$A 2$ & & 40 & $20^{* 1}$ & 0.325 & 0.65 & & 65 \\
\hline$B 1$ & 40 & & $20^{* 2}$ & 0.325 & 0.65 & & 65 \\
\hline$B 2$ & & 40 & $20^{* 2}$ & 0.325 & 0.65 & & 65 \\
\hline$C 1$ & 40 & & $20^{* 3}$ & 0.325 & 0.65 & & 65 \\
\hline$C 2$ & & 40 & $20^{* 3}$ & 0.325 & 0.65 & & 65 \\
\hline$D 1$ & 40 & & & 0.325 & 0.65 & 2 & 65 \\
\hline$D 2$ & & 40 & & 0.325 & 0.65 & 2 & 65 \\
\hline$E 1$ & 40 & & & 0.325 & 0.65 & & 65 \\
\hline$E 2$ & & 40 & & 0.325 & 0.65 & & 65 \\
\hline
\end{tabular}

Yolk $^{* 1}$ Albumen ${ }^{* 2}$ Yolk + Albumen ${ }^{* 3}$. 
ing to note that even at $5^{\circ} \mathrm{C}$ there was some growth at the rate of around $0.89 \mathrm{~mm} /$ day in terms of colony diameter.

As shown in Table 2, initial media $\mathrm{pH}$ values studied did not have much effect on mycelial growth. The highest colony growth was obtained at $\mathrm{pH}$ 7. This was similar to previous studies on other fungal species [16-18]. However, $\mathrm{pH} 7$ was not statistically different from $\mathrm{pH} 6$ and 8 (p > 0.05). Amin et al. [20] also reported that no significant variations were found in growth rate of $O$. sinensis mycelium growing in PDA Media with different initial $\mathrm{pH}$.

\subsection{Mycelial Growth in Various Cereal Grains Agar Media}

In terms of thickness of the colonies, a remarkable difference was observed between the medium with and without peptone for each of the six studied grains (Figure 1). All the media with peptone produced thick and white mycelia. Millet agar (MA) and white sorghum agar (WSA) produced very thin and transparent colonies. The colony in brown rice agar (BRA) was thin and translucent towards the edge. Lye agar (LA) and oats agar (OA) produced mycelial mats which were white, thin and without well developed aerial mycelium. In wheat agar (WA) the colony was white and with well developed aerial mycelium just like in grains media with peptone. As shown in Figure 2, apart from in wheat and millet, addition of peptone did not have a significant effect in terms of colony diameters $(p>0.05)$ in the other four grains. The highest colony diameter (79.99 mm), in 15 days, was obtained in wheat peptone agar (WPA). However this was not significantly different from colony diameters in BRA (68.89 mm) and LA (68.44 mm). The lowest colony diameter was recorded in MA (56.75 mm).

The results show that inclusion of peptone to the cereal grains agars is necessary for best results in mycelial growth of $P$. hepiali. Apart from wheat, the other grains

Table 2. Effect of temperature and initial pH on mycelial growth of Paecilomyces hepiali in PDA.

\begin{tabular}{cccc}
\hline $\begin{array}{c}\text { Temperature } \\
\text { (Deg. Celsius) }\end{array}$ & $\begin{array}{c}\text { Colony } \\
\text { diameter }(\mathrm{mm})\end{array}$ & Initial pH & $\begin{array}{c}\text { Colony } \\
\text { diameter }(\mathrm{mm})\end{array}$ \\
\hline 5 & $12.53 \pm 0.50^{\mathrm{f}}$ & 5.0 & $56.66 \pm 3.02^{\mathrm{b}}$ \\
10 & $28.59 \pm 0.60^{\mathrm{e}}$ & 6.0 & $61.73 \pm 1.86^{\mathrm{a}}$ \\
15 & $36.13 \pm 0.83^{\mathrm{d}}$ & 7.0 & $61.79 \pm 1.50^{\mathrm{a}}$ \\
20 & $55.80 \pm 2.38^{\mathrm{b}}$ & 8.0 & $60.53 \pm 1.43^{\mathrm{a}}$ \\
25 & $61.86 \pm 0.96^{\mathrm{a}}$ & 9.0 & $59.20 \pm 1.70^{\mathrm{ab}}$ \\
30 & $31.80 \pm 0.93^{\mathrm{c}}$ & & \\
\hline
\end{tabular}

Values in the same column with different superscript letters differ significantly according to Tukey's Multiple Comparisons test $(p<0.05)$. Each value is a mean \pm SD of five replicates measured on the $14^{\text {th }}$ day after inoculation. were not that favourable in supporting mycelial growth without addition of peptone. In their study on nutritional requirements of mycelial growth of Cordyceps sinensis in submerged culture, Dong and Yao [21] found the media supplied with peptone and beef extract to be the most effective for the mycelial growth of $C$. sinensis. They also indicated that this fungus had greater preference on organic nitrogen, which is common in fungi. This could also explain why in this study all the cereal grains agar media supplied with peptone were favourable in sup-
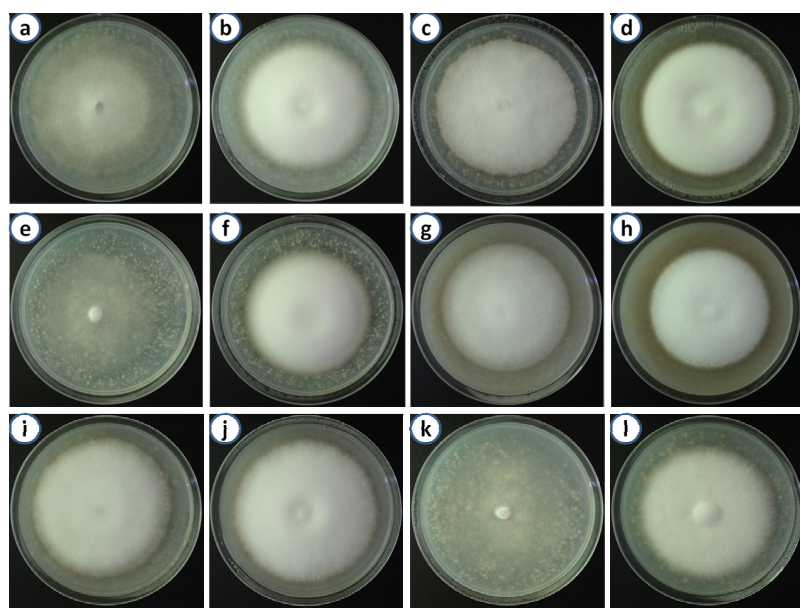

Figure 1. Colonies of Paecilomyces hepiali in different cereal grains agars on the $15^{\text {th }}$ day after inoculation: a-brown rice agar (BRA); b-brown rice peptone agar (BRPA); c-lye agar (LA); d-lye peptone agar (LPA); e-millet agar (MA); f-millet peptone agar (MPA); g-oats agar (OA); h-oats peptone agar (OPA); i-wheat agar (WA); $j$-wheat peptone agar (WPA); k-white sorghum agar (WSA); l-white sorghum peptone agar (WSPA).

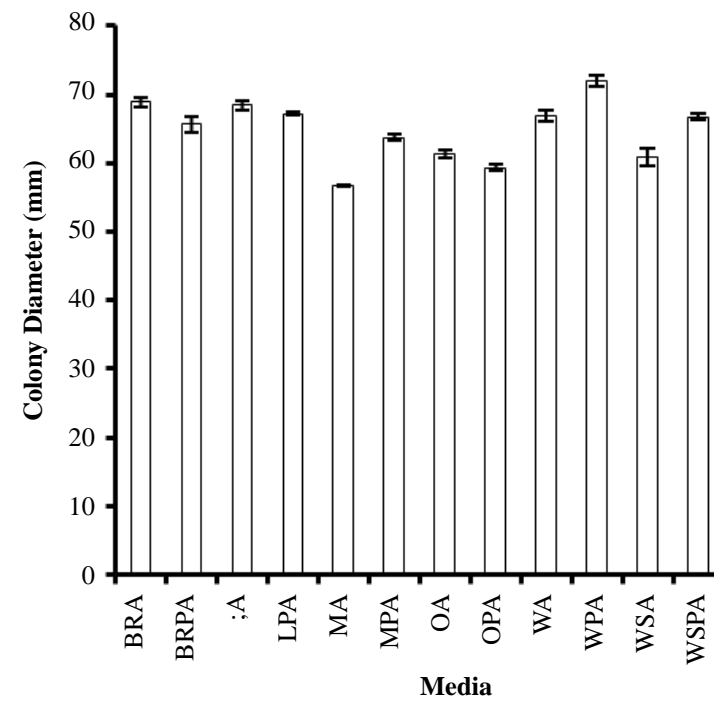

Figure 2. Mycelial growth of Paecilomyces hepiali in various cereal grains agar media. Each bar represents the mean value of three replicates measured on the $15^{\text {th }}$ day after inoculation. The error bars represent standard error. 
porting mycelial growth of $P$. hepiali.

\subsection{Effect of Carbon Source on Mycelial Growth}

The growth response of $P$. hepiali to various carbon sources investigated was significant (Figures 3 and 4). The most favourable carbon sources were mannose, fructose and glucose with colony diameter values of 68.20 $\mathrm{mm}, 67.73 \mathrm{~mm}$ and $67.13 \mathrm{~mm}$ respectively, in 14 days. These values were not statistically different $(\mathrm{p}>0.05)$.

Galactose was the least in supporting mycelial growth of $P$. hepiali with colony diameter value of $35.6 \mathrm{~mm}$ after 14 days from inoculation. However, it was better than cellulose, lactose and control media in terms of colony density. Growth in maltose, mannitol and sucrose were also quite good. The media without carbon source resulted into a thin mycelial mat that was almost translucent (Figure 4). Almost the same observation was made on media with cellulose and lactose.

The poor growth in the control media confirms the necessity of a carbon source for the good growth and development of $P$. hepiali. All fungi depend on organic carbon; it is the qualitatively and quantitatively most important nutritional element [22]. Fungi use a wide variety of organic compounds for their carbon requirements. These compounds provide both the structural carbon for all organic compounds as well as providing energy for metabolic processes. The carbon sources include monosaccharides, polysaccharides, organic acids, amino acids, alcohols, and natural products, such as cellulose and lignin [23].

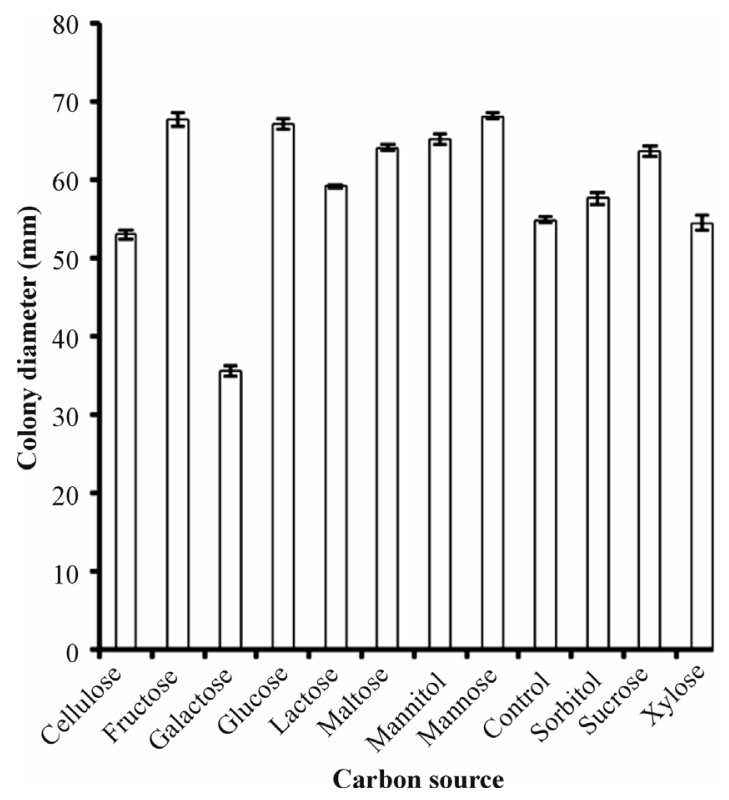

Figure 3. Mycelial growth of Paecilomyces hepiali in various carbon sources. Each bar represents the mean value of five replicates measured on the $14^{\text {th }}$ day after inoculation. The error bars represent standard error.
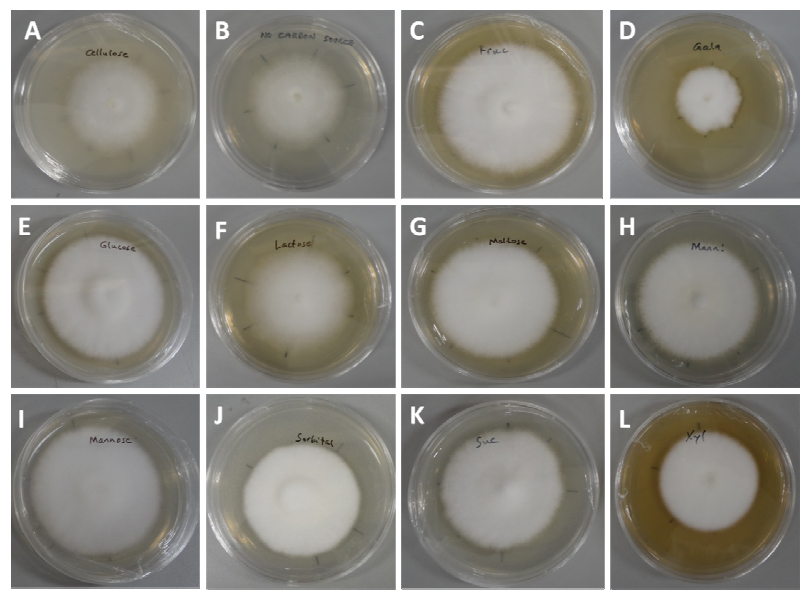

Figure 4. Colonies of Paecilomyces hepiali after 14 days of growth in various carbon sources: A-cellulose; B-control (no carbon source); C-fructose; D-galactose; E-glucose; Flactose; G-maltose; H-mannitol; I-mannose; J-sorbitol; Ksucrose; L-xylose.

In their study with Waterborne Conidial fungi, Sati and Bisht [24] found cellulose to be a poor source of carbon for all the four isolates of the fungi studied. They explained that this could probably be because of lack of extracellular enzyme(s) necessary to degrade cellulose. This could also be the explanation for poor mycelial growth of $P$. hepiali in cellulose. Sung et al. [19] reported that the mycelia of Cordyceps cardinalis in media with lactose as a carbon source was thinly dense. This is similar to the findings on $P$. hepiali in this study. Lactose is a disaccharide made up of galactose and glucose molecules. In this study, the least colony diameter value was obtained in galactose as a carbon source. Perhaps the poor mycelial growth of $P$. hepiali in lactose was due to the presence of galactose in its structure. However, we do not have an explanation as to why galactose, a simple sugar, was found to be a poor carbon source for mycelial growth of $P$. hepiali in agar media. Imtiaj et al. [13] found lactose and galactose to be the most unfavourable carbon sources for various edible mushrooms. Almost similar results are reflected in this study for P. hepiali.

\subsection{Effect of Nitrogen Source}

Among the nitrogen sources tested, peptone, beef extract and yeast extract resulted in the best mycelial growth (Table 3 and Figure 5).

The highest colony diameter (66.06 mm), in 14 days, was obtained in medium with peptone. However, this was not significantly different from values recorded in beef extract $(64.60 \mathrm{~mm})$ and yeast extract $(64.26 \mathrm{~mm})$. These three organic nitrogen sources produced very well developed aerial mycelia. Medium without nitrogen source produced a very thin and transparent mycelial mat (Figure 5). However, the colony diameter was larger than 

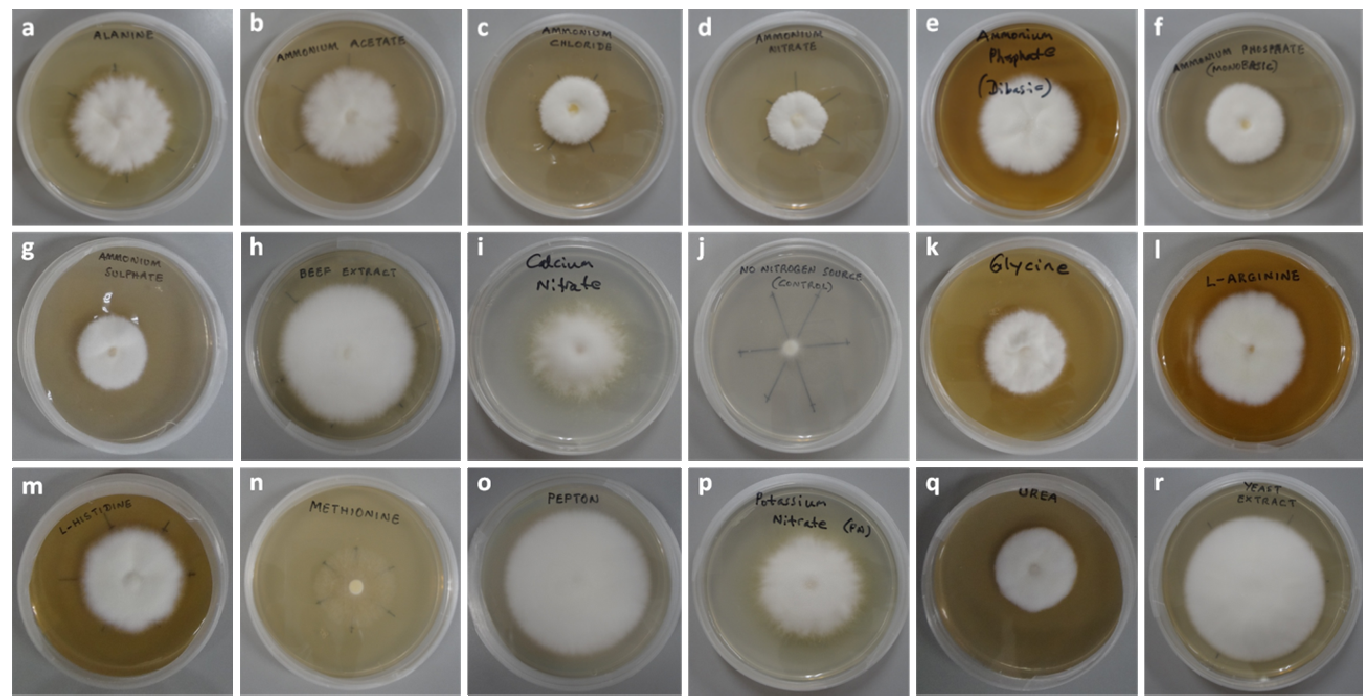

Figure 5. Colonies of Paecilomyces hepiali after 14 days of growth in various nitrogen sources: a-alanine; b-ammonium acetate; c-ammonium chloride; d-ammonium nitrate; e-ammonium phosphate, dibasic; f-ammonium phosphate, monobasic; g-ammonium sulfate; h-beef extract; i-calcium nitrate; j-control (no nitrogen source); k-glycine; l-L-arginine; m-L-histidine; n-L-methionine; o-peptone; p-potassium nitrate; q-Urea; r-yeast extract. Each medium was prepared by replacing peptone

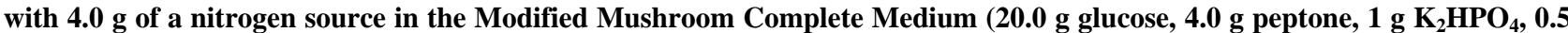
$\mathrm{g} \mathrm{MgSO}_{4}, 0.5 \mathrm{~g} \mathrm{KH}_{2} \mathrm{PO}_{4}, 20.0$ g agar and $1000 \mathrm{ml}$ distilled water).

Table 3. Effect of nitrogen source on mycelial growth of Paecilomyces hepialid.

\begin{tabular}{|c|c|}
\hline Nitrogen source & Colony diameter (mm) \\
\hline Alanine & $47.26 \pm 1.21^{\mathrm{d}}$ \\
\hline Ammonium acetate & $45.93 \pm 1.36^{\mathrm{d}}$ \\
\hline Ammonium chloride & $33.00 \pm 1.05^{\mathrm{h}}$ \\
\hline Ammonium nitrate & $27.26 \pm 0.64^{\mathrm{i}}$ \\
\hline Ammonium phosphate, dibasic & $46.06 \pm 0.43^{\mathrm{d}}$ \\
\hline Ammonium phosphate, monobasic & $37.40 \pm 0.86^{\text {ef }}$ \\
\hline Ammonium sulfate & $32.53 \pm 1.12^{\mathrm{h}}$ \\
\hline Beef extract & $64.60 \pm 1.40^{a}$ \\
\hline Calcium nitrate & $46.46 \pm 1.17^{\mathrm{d}}$ \\
\hline Glycine & $39.86 \pm 0.77^{\mathrm{e}}$ \\
\hline L-Arginine & $50.20 \pm 2.09^{c}$ \\
\hline L-Histidine & $47.86 \pm 0.69^{\mathrm{cd}}$ \\
\hline L-Methionine & $33.73 \pm 1.62^{\text {gh }}$ \\
\hline No nitrogen source & $54.33 \pm 1.06^{\mathrm{b}}$ \\
\hline Peptone & $66.06 \pm 0.80^{a}$ \\
\hline Potassium nitrate & $54.27 \pm 1.74^{\mathrm{b}}$ \\
\hline Urea & $36.00 \pm 1.18^{\mathrm{fg}}$ \\
\hline Yeast extract & $64.26 \pm 0.43^{a}$ \\
\hline
\end{tabular}

Values in the same column with different letters differ significantly according to Tukey's Multiple Comparisons test $(p<0.05)$. Each value is a mean \pm SD of five replicates measured on the $14^{\text {th }}$ day after inoculation. Medium for each nitrogen source was prepared by replacing peptone with $4.0 \mathrm{~g}$ of the nitrogen source in the Modified Mushroom Complete Medium (20.0 g glucose, 4.0 g peptone, $1 \mathrm{~g} \mathrm{~K}_{2} \mathrm{HPO}_{4}, 0.5 \mathrm{~g} \mathrm{MgSO}_{4}, 0.5 \mathrm{~g} \mathrm{KH}_{2} \mathrm{PO}_{4}, 20.0 \mathrm{~g}$ agar and $1000 \mathrm{ml}$ distilled water). all nitrogen sources except for peptone, beef extract and yeast extract (Table 3). Methionine resulted in a very thin and almost transparent colony. After fourteen days of incubation, all other inorganic nitrogen sources produced colony diameters ranging from $27.26 \mathrm{~mm}$ to 54.27 $\mathrm{mm}$. Among the inorganic nitrogen sources, potassium nitrate produced the best mycelial growth with a well developed aerial mycelium and colony diameter of 54.27 mm.

This experiment has shown that organic nitrogen sources are, by far, more favourable than inorganic nitrogen sources in supporting mycelial growth of $P$. hepiali. This is similar to findings in studies of other fungi. Sung et al. [17] reported that nitrogen sources such as yeast extract, peptone and tryptone are favourable for mycelial growth of $O$. longissima as in other Cordyceps and allied species. Dong and Yao [21] pointed out that $C$. sinensis had greater preference on organic nitrogen, which is common in fungi.

\subsection{Growth in Rice-Based Media}

The results in Table 4 show that brown rice produced better fruit bodies yield than polished rice. Media supplemented with peptone ( $D 1$ and $D 2$ ) produced the highest yield of fruit bodies followed by media supplemented with egg yolk ( $A 1$ and $A 2$ ). Media not supplemented with any egg part or peptone produced the smallest yield of fruit bodies. The findings of this study suggest that addition of an organic nitrogen source to the media enhances fruit body yield of $P$. hepiali. In their study on Cordyceps 
Table 4. Days to primordia formation and fruit body yield of Paecilomyces hepiali in various rice based media.

\begin{tabular}{ccc}
\hline Media & $\begin{array}{c}\text { Days to primordia } \\
\text { formation }\end{array}$ & $\begin{array}{c}\text { Fresh weight yield of } \\
\text { fruit bodies (g) }\end{array}$ \\
\hline$A 1$ & 37 & $17.4 \pm 0.8^{\mathrm{bcd}}$ \\
$A 2$ & 33 & $\mathbf{1 8 . 5} \pm \mathbf{0 . 7}^{\mathrm{ab}}$ \\
$B 1$ & 39 & $14.2 \pm 0.4^{\mathrm{e}}$ \\
$B 2$ & 35 & $16.1 \pm 0.6^{\mathrm{d}}$ \\
$C 1$ & 38 & $16.5 \pm 0.4^{\mathrm{cd}}$ \\
$C 2$ & 34 & $17.2 \pm 0.8^{\mathrm{bcd}}$ \\
$D 1$ & 33 & $\mathbf{1 8 . 2} \pm \mathbf{0 . 9}^{\mathrm{abc}}$ \\
$D 2$ & 31 & $\mathbf{1 9 . 3} \pm \mathbf{0 . 8}^{\mathrm{a}}$ \\
$E 1$ & 37 & $13.2 \pm 0.5^{\mathrm{e}}$ \\
$E 2$ & 36 & $13.7 \pm 0.3^{\mathrm{e}}$ \\
\hline
\end{tabular}

Values in the same column not sharing same superscript letter are significantly different according to Tukey's Multiple Comparisons test $(p<0.05)$. Each value is a mean \pm SD of three determinations.

cardinalis, Kim et al. [25] found brown rice to be better than polished rice in size as well as fresh weight of fruit bodies. They also reported that addition of silkmoth pupa and larvae to the media slightly enhanced production of fruit bodies. The higher fruit body yield obtained in brown rice media was not a surprising result considering that brown rice is superior to polished rice in terms of nutrients. As Babu et al. [26] indicated, in rice milling, the bran layers and germ removed during polishing are high in fiber, vitamins, minerals as well as protein. Therefore, their removal results in loss of these nutrients.

As shown in Table 4, the highest fruit body yield of $19.3 \mathrm{~g}$ was obtained in medium $\mathrm{D} 2$ (40 g brown rice, 0.325 g glucose, 0.65 g sucrose, 2 g peptone and $65 \mathrm{ml}$ corn steep liquor). This was followed by a yield of $18.5 \mathrm{~g}$ in medium A2 (40 g brown rice, $20 \mathrm{~g}$ egg york, 0.32 glucose, $0.65 \mathrm{~g}$ Sucrose and $65 \mathrm{ml}$ corn steep liquor). In terms of fresh weight yield, these media were not statistically different $(p>0.05)$. However, if we were to calculate the Biological Efficiency (BE) D2 would definitely have a much higher $\mathrm{BE}$ than $\mathrm{A} 2$ because the total mass of ingredients in $A 2$ are substantially more than that of $D 2$. That makes $D 2$ the most suitable medium amongst all the media studied.

Days to primordia formation for all the media ranged from 31 to 39. D2 took the least number of days for primordia to start forming and $B 1$ took the longest time. The general trend was that the medium with brown rice, in each pair, took fewer days than the one with polished rice in days to primordia formation (Table 4).

\section{Conclusion}

This study found the most favourable temperature range for the growth of $P$. hepiali mycelia to be $25^{\circ} \mathrm{C}$. The mycelial growth response to agar media with various initial $\mathrm{pH}$ values did not show remarkable differences. However, $\mathrm{pH} 6$ to $\mathrm{pH} 9$ gave the best growth. Therefore, we recommend this $\mathrm{pH}$ for the best growth and development of $P$. hepiali mycelia in agar media. Addition of peptone to cereal grains (lye, wheat, millet, white sorghum, brown rice and oats) agar media is necessary for best mycelial growth of $P$. hepiali. Agars made with powders from grains alone do not support good mycelial growth of this fungus. The general composition of the grain agar, as used in this study, is 20 g grain powder, $4 \mathrm{~g}$ peptone, 15 g agar and $1000 \mathrm{ml}$ distilled water. Out of the eleven carbon sources tested, mannose, fructose and glucose were found to be the most favourable for mycelial growth of $P$. hepiali. With regard to nitrogen sources, this fungus preferred organic nitrogen sources namely peptone, beef extract and yeast extract. Brown rice was found to be better than polished rice in yield of fruit bodies of this fungus. The medium with $40 \mathrm{~g}$ brown rice, 0.325 g glucose, 0.65 $\mathrm{g}$ sucrose, $2 \mathrm{~g}$ peptone and $65 \mathrm{ml}$ corn steep liquor was found to be the best in fresh weight yield of $P$. hepiali fruiting bodies. Supplementation of a protein source to the media was found to be a remarkable enhancer of fruit body yield.

\section{REFERENCES}

[1] J.-S. Zhu, L. Gao, X.-H. Li, Y.-S. Yao, J.-Q. Zhao, Y.-J Zhou and J.-H. Lu, "Maturational Alteration of Oppositely Orientated rDNA and Differential Proliferation of GCand AT-biased Genotypes of Ophiocordyceps sinensis and Paecilomyces hepiali in Natural Cordyceps sinensis," American Journal of Biomedical Sciences, Vol. 2, No. 3, 2010, pp. 217-238. http://dx.doi.org/10.5099/aj100300217

[2] G. S. Barseghyan, J. C. Holliday, T. C. Price, L. M. Madison and S. P. Wasser, "Growth and Cultural-Morphological Characteristics of Vegetative Mycelia of Medicinal Caterpillar Fungus Ophiocordyceps sinensis G.H. Sung et al. (Ascomycetes) Isolates from Tibetan Plateau (P.R. China),” International Journal of Medicinal Mushrooms, Vol. 13, No. 6, 2011, pp. 565-581.

http://dx.doi.org/10.1615/IntJMedMushr.v13.i6.90

[3] G.-H. Sung, N. L. Hywel-Jones, J.-M. Sung, J. J. Luangsa-ard, B. Shrestha and J. W. Spatafora, "Phylogenetic Classification of Cordyceps and the Clavicipitaceous Fungi,” Studies in Mycology, Vol. 57, No. 1, 2007, pp. 559. http://dx.doi.org/10.3114/sim.2007.57.01

[4] Y.-Q. Chen, N. Wang, L.-H. Qu, T.-H. Li, W.-M. Zhang, "Determination of the Anamorph of Cordyceps Sinensis Inferred from Analysis of the Ribosomal DNA Internal Transcribed Spacers and 5.8S rDNA," Biochemical Systematics and Ecology, Vol. 29, No. 6, 2001, pp. 597-607. http://dx.doi.org/10.1016/S0305-1978(00)00100-9

[5] Z.-Y. Liu, Y.-J. Yao, Z.-Q. Liang, A.-Y. Liu, D. N. Pegler and M. W. Chase, "Molecular Evidence for Anamor- 
ph-Teleomorph Connection in Cordyceps sinensis," Mycological Research, Vol. 105, No. 7, 2001, pp. 827-832. http://dx.doi.org/10.1017/S095375620100377X

[6] Z.-Y. Liu, Z.-Q. Liang, A.-Y. Liu, Y.-J. Yao, K. D. Hyde and Z.-N. Yu, "Molecular Evidence for Teleomorph-Anamorph Connections in Cordyceps Based on ITS-5 $\pm 8 \mathrm{~S}$ rDNA Sequences,” Mycological Research, Vol. 106, No. 9, 2002, pp. 1100-1108. http://dx.doi.org/10.1017/S0953756202006378

[7] A. K. Bhandari, J. S. Negi, V. K. Bisht, M. K. Bharti and N. Singh, "Chemical Constituent, Inorganic Elements and Properties of Cordyceps sinensis-A Review," Nature and Science, Vol. 8, No. 9, 2010.

[8] S.-J. Yu, Y. Zhang, C.-R. Li, Q. Zhang, Z.-Y. Ma and M.Z. Fan, "Optimization of Ultrasonic Extraction of Mycelial Polysaccharides from Paecilomyces hepiali Using Response Surface Methodology and Its Antioxidant Activity,” African Journal of Biotechnology, Vol. 10, No. 75, 2011, pp. 17241-17250.

[9] A. Thakur, R. Hui, Z. Hongyan, Y. Tian, C. Tianjun and C. Mingwei, "Pro-Apoptotic Effects of Paecilomyces hepiali, a Cordyceps sinensis Extract on Human Lung Adenocarcinoma A549 Cells in Vitro,” Journal of Cancer Research and Therapeutics, Vol. 7, No. 4, 2011, pp. 421426. http://dx.doi.org/10.4103/0973-1482.92007

[10] P. Stamets, "Growing Gourmet and Medicinal Mushrooms,” 3rd Edition, Ten Speed Press, California, 2000, $87 \mathrm{p}$.

[11] J. C. Holliday, P. Cleaver, M. Loomis-Powers and D. Patel, “Analysis of Quality and Techniques for Hybridization of Medicinal Fungus Cordyceps sinensis (Berk.) Sacc. (Ascomycetes),” International Journal of Medicinal Mushrooms, Vol. 6, No. 2, 2004, pp. 151-164. http://dx.doi.org/10.1615/IntJMedMushr.v6.i2.60

[12] “New Chapter Inc. LifeShield Cordyceps,” 2013. http://www.newchapter.com/mushrooms/lifeshield-cordy ceps

[13] A. Imtiaj, C. Jayasinghe, G. W. Lee and T. Lee, “Comparative Study of Environmental and Nutritional Factors on the Mycelial Growth of Edible Mushrooms," Journal of Culture Collections, Vol. 6, 2008, pp. 97-105. http://www.nbimcc.org/JCC/2009/JCC09612/JCC09612S .htm

[14] S. M. Shim, K. R. Lee, S. H. Kim, K. H. Im, J. W. Kim, U. Y. Lee, J. O. Shim, M. W. Lee and T. S. Lee, “The Optimal Culture Conditions Affecting the Mycelial Growth and Fruiting Body Formation of Paecilomyces fumosoroseus,” Mycobiology, Vol. 31, No. 4, 2003, pp. 214-220. http://dx.doi.org/10.4489/MYCO.2003.31.4.214

[15] B. Yang and S. Ohga, "Growth Characteristic and Polysaccharide Content of Cordyceps sobolifera," Journal of
Food Function, Vol. 4, No. 1, 2008, pp. 1-6.

[16] F. Sasaki, T. Miyamoto, Y. Tamai and T. Yajima, "Optimum Temperature and $\mathrm{pH}$ for Mycelial Growth of Cordyceps nutans Pat. (Ascomycetes),” International Journal of Medicinal Mushrooms, Vol. 7, No. 1-2, 2005, pp. 301304. http://dx.doi.org/10.1615/IntJMedMushr.v7.i12.270

[17] G. Sung, B. Shrestha, S. Han and J. Sung, "Growth and Cultural Characteristics of Ophiocordyceps longissima Collected from Korea,” Mycobiology, Vol. 39, No. 2, 2011 , pp. 85-91. http://dx.doi.org/10.4489/MYCO.2011.39.2.085

[18] G. Sung, B. Shrestha, S. Han and J. Sung, "Cultural Characteristics of Ophiocordyceps heteropoda Collected from Korea,” Mycobiology, Vol. 39, No. 1, 2011, pp. 1-6. http://dx.doi.org/10.4489/MYCO.2011.39.1.001

[19] G. Sung, B. Shrestha, S. Han, S. Kim and J. Sung, "Growth and Cultural Characteristics of Cordyceps cardinalis Collected from Korea,” Mycobiology, Vol. 38, No. 4, 2010, pp. 274-281.

http://dx.doi.org/10.4489/MYCO.2010.38.4.274

[20] S. M. R. Amin, N. Alam, M. Tania and M. A. Khan, "Study of Mycelial Growth of Cordyceps sinensis on Different Culture Media, at Different $\mathrm{pH}$ Level and Temperapture,” Bangladesh Journal of Mushroom, Vol. 2, No. 2, 2008, pp. 43-48.

[21] C.-H. Dong and Y.-J. Yao, "Nutritional Requirements of Mycelial Growth of Cordyceps sinensis in Submerged Culture,” Journal of Applied Microbiology, Vol. 99, 2005, pp. 483-492. http://dx.doi.org/10.1111/j.1365-2672.2005.02640.x

[22] D. H. Jennings and G. Lysek, "Fungal Biology: Understanding the Fungal Lifestyle,” 2nd Edition, BIOS Scientific Publishers Ltd., New York, 1999, p. 45.

[23] P. G. Miles and S. T. Chang, "Mushroom Biology-Concise Basics and Current Developments,” World Scientific, 1997, p. 41.

[24] S. C. Sati and S. Bisht, "Utilization of Various Carbon Sources for the Growth of Waterborne Conidial Fungi," Mycologia, Vol. 98, No. 5, 2006, pp. 678-681. http://dx.doi.org/10.3852/mycologia.98.5.678

[25] S.-Y. Kim, B. Shrestha, G.-H. Sung, S.-K. Han and J.-M. Sun, "Optimum Conditions for Artificial Fruiting Body Formation of Cordyceps cardinalis,” Mycobiology, Vol. 38, No. 2, 2010, pp. 133-136. http://dx.doi.org/10.4489/MYCO.2010.38.2.133

[26] P. D. Babu, R. S. Subhasree, R. Bhakyaraj and R. Vidhyalakshmi, "Brown Rice-Beyond the Color Reviving a Lost Health Food-A Review," American-Eurasian Journal of Agronomy, Vol. 2, No. 2, 2009, pp. 67-72. 